\title{
Sostenibilidad del sistema sanitario: compromiso ético de los médicos
}

\author{
Prof. Dr. Juan Viñas Salas \\ Catedrático de Cirugía y Ex-Rector de la Universidad de Lleida.
}

La salud es un bien preciado por todas las personas. La sociedad del bienestar exige que el Estado se responsabilice de su salud. En nuestro país la asistencia sanitaria está garantizada por el Estado, estando transferida a las Comunidades Autónomas. Es una conquista de la sociedad que da tranquilidad a la población, pues cuando una persona cae enferma, sabe que será atendida por un médico de familia, por un especialista o por urgencias de un hospital o ingresada si lo precisa sin que le pidan dinero; y que los actos médicos y las medicinas más caras (MHDA - Medicación Hospitalaria de Dispensación Ambulatoria) no las han de pagar. Somos una población privilegiada pues solo disfruta de este derecho una pequeña parte de la humanidad del planeta.

La asistencia sanitaria cuesta mucho dinero que los ciudadanos pagamos con nuestros impuestos. Cada año es más cara por varios motivos, sobretodo porque las personas vivimos más años y porque los constantes avances científico-tecnológicos ponen a disposición de los médicos máquinas diagnósticas y terapéuticas y medicamentos cada vez más sofisticados y caros, ya que su descubrimiento y aceptación por las agencias suponen grandes inversiones que realizan las empresas privadas, cuyos accionistas desean ganar dinero. Es muy escasa la investigación pública en estos campos. También las exigencias de la máxima seguridad para el enfermo y las mejoras hoteleras de los centros sanitarios incrementan el coste de la asistencia sanitaria.

En un sistema capitalista de libre mercado como el que tenemos el mercado sanitario no puede ser libre del todo, ya que la asistencia sanitaria está socializada y el mercado es cautivo, pues los compradores están obligados a ello. Son necesarias legislaciones y acuerdos que controlen este mercado sanitario, y unos gobiernos valientes y comprometidos que no caigan en la servidumbre de los grandes capitalistas. Hace pocos años vivimos el escándalo del tratamiento de la hepatitis C, desde la aparición de los antivirales en 2012, la aprobación de la financiación pública con restricciones en 2014 debido al alto coste del tratamiento, que no se generalizó hasta 2017. Supuso para los sistemas de salud un coste adicional no previsto inicialmente que tuvieron que asumir progresivamente, ya que el Sofosbuvir estaba patentado y tenía un precio muy elevado y cada país negociaba un precio diferente $e^{1,2}$.

Cada año crece el porcentaje de dinero destinado a la sanidad por encima del PBI, hecho que aumenta la deuda del país, haciendo prever que algún día dejará de ser sostenible. España destina a la sanidad dos puntos menos que la media de los países de la OCDE: 5,2\% frente al 7,3\%, aunque estas cifras varían según como se reco$\mathrm{jan}^{3}$. La realidad es que existen listas de espera tanto para diversas cirugías como para pruebas diagnósticas y visitas al especialista, que suponen un deterioro de la asistencia para los pacientes: 168.540 personas estaban esperando visita al especialista en Galicia el año 2019, 9.707 más de 3 meses, habiendo otras comunidades autónomas con más listas de espera ${ }^{4,5}$.

Para cuadrar los presupuestos sanitarios y ofrecer una asistencia sanitaria de calidad y equitativa o se disminuye el gasto o se incrementan los presupuestos, lo que se consigue aumentando la presión fiscal a la ciudadanía, y esto tiene un límite o se empobrece al país empeorando la situación, aunque una distribución justa de los impuestos es necesaria, con más impuestos directos, haciendo que los que más tienen paguen más, haya menos fraude fiscal.

¿Qué hacer para racionalizar el gasto sanitario y sacar más rendimiento al dinero invertido en la sanidad? Hay que actuar a todos los niveles.

Queda claro que urge cambiar la política sanitaria para hacer frente a este grave problema sanitario, que se acentúa cada año. Es responsabilidad de los políticos que realizan macrogestión: hacen las leyes y elaboran y aprueban los presupuestos. No estoy seguro que todos ellos sean conscientes 


\section{"El estilo de vida de los ciudadanos debe cambiar para mejorar su salud, prevenir enfermedades y así disminuir el gasto sanitario"}

que cuando aprietan el botón en el Parlamento con unas cifras determinadas están manteniendo o creando listas de espera, decidiendo que no aumentan las camas generales y de UVI, el número de médicos y de los otros profesionales de la salud, la reposición de aparataje médico, etc., con las consecuencias que ello representa para los enfermos.

También la organización de la asistencia sanitaria debe mejorar y ponerse al día, ya que estamos en el siglo XXI y en el sistema público seguimos arrastrando legislación de la época de la dictadura. Los cambios de los estatutos y reglamentos de régimen interior son necesarios para dar más protagonismo a los profesionales sanitarios, más corresponsabilidad y capacidad de decisión con su correspondiente rendición de cuentas. Especialmente a los médicos que son los líderes naturales del sistema por su formación y papel social.

Los ciudadanos hacemos autogestión con nuestro estilo de vida. El estilo de vida de los ciudadanos debe cambiar para mejorar su salud, prevenir enfermedades y así disminuir el gasto sanitario. Una dieta saludable y hacer ejercicio evita muchas enfermedades. Beber con moderación bebidas alcohólicas, no fumar, reducir el estrés, no destruir el medio ambiente y otras varias acciones evitan enfermedades y ahorran mucho dinero que se puede utilizar para otras necesidades del sistema sanitario. Se deben hacer distintas acciones transversales en varios ministerios y consejerías para obtener frutos.

Los gestores de los centros sanitarios realizan mesogestión: Ellos reciben unos presupuestos de las consejerías de sanidad y su obligación ética es que se obtenga con ellos el máximo de salud con el mínimo "coeficiente de roce". Deben distribuir el dinero con la máxima eficiencia resistiendo a las presiones que puedan tener para favorecer a unos, aunque otros menos "poderosos" tienen más necesidad e invertir en sus servicios resolvería mayores defectos. Deben cuadrar el presupuesto; no es su responsabilidad directa el recibir más o menos dinero, por lo que no se les puede exigir.

Los profesionales de la salud hacemos microgestión. Tenemos unos recursos a nuestra disposición- desde despachos, aparatos, capacidad de indicar actuaciones médicas, de recetar, etc. y debemos usarlos de la manera más eficiente posible. Tenemos una gran responsabilidad en colaborar en la sostenibilidad del sistema sanitario. De hecho, nosotros lo podemos hacer quebrar dependiendo de nuestra actuación.

Si podemos diagnosticar una enfermedad con menos gasto en pruebas diagnósticas debemos hacerlo. Se requiere una habilidad clínica fruto de formación y experiencia y aceptar que no existe el riesgo cero ni la certeza absoluta. Muchas veces mejorar un 1\% la certeza supone una gran inversión. Debemos recetar aquellos medicamentos eficaces que sean más baratos, siendo eficientes. Los médicos debemos defender siempre a los pacientes que atenemos, pero al mismo tiempo debemos tener en cuenta no malgastar para que haya recursos para los siguientes pacientes. Ser médicos bien formados actuando con calidad asistencial y realizando los mínimos errores diagnósticos y terapéuticos no sólo beneficia al enfermo concreto que atendemos, sino también a los demás al ahorrar dinero que supone el tratar las complicaciones y efectos secundarios de los errores médicos.

\section{BIBLIOGRAFÍA}

1. Vigario A. «España cura a todos los pacientes de hepatitis C tras gastar 1800 millones». El economista. 20 de noviembre de 2017

2. https://www.diariofarma.com/2016/11/25/hepatitis-c-30-precios-diferentesproblema

3. https://www.redaccionmedica.com/secciones/sanidad-hoy/espana-reduce-unadecima-su-gasto-sanitario-publico-y-esta-la-17-de-europa-4821

4. https://www.epdata.es/datos/listas-espera-sanidad-publica-datos-graficos-comunidad-autonoma/28/galicia/301

5. https://www.sergas.es/Asistencia-sanitaria/Documents/1164/web_cex_201912_SAACl-\%C3\%81REA_2019-12.pdf 